\title{
Influence of reservoir geometry and conditions on the seismic response of arch dams
}

\author{
F. Garcia ${ }^{a}$, J.J. Aznárez ${ }^{a}$, H. Cifuentes ${ }^{b}$, F. Medina ${ }^{b}$ and O. Maeso ${ }^{a}$
}

(a) Instituto Universitario de Sistemas Inteligentes y Aplicaciones Numéricas en Ingeniería (SIANI). Edificio Central del Parque Científico y Tecnológico. Campus Universitario de Tafira. Universidad de Las Palmas de Gran Canaria. 35017 Las Palmas de Gran Canaria. Spain. fgarcia@dic.ulpgc.es,jjaznarez@siani.es,omaeso@siani.es

(b) Grupo de Estructuras, Escuela Técnica Superior de Ingeniería, Universidad de Sevilla, Camino de los Descubrimientos s/n, 41092 Sevilla, Spain bulte@us.es,medinaencina@us.es

\section{Abstract}

An analysis of the influence that reservoir levels and bottom sediment properties (especially on the degree of saturation) have on the dynamic response of arch dams is carried out. For this purpose, a Boundary Element Model developed by the authors that allows the direct dynamic study of problems that incorporate scalar (dammed up water), viscoelastic (dam and soil site) and poroelastic media (bottom sediments in the reservoir) is used. All of the regions are discretized using boundary elements, later formulating equations of compatibility and equilibrium that allow their interaction to be rigorously established. The seismic excitation consists in plane longitudinal waves ( $\mathrm{P}$ waves) and shear waves ( $\mathrm{S}$ waves) impinging the dam site with an angle of vertical incidence. The analysis is carried out in the frequency domain, and the time response is obtained, for synthesized artificial accelerograms defined in terms of the elastic response spectrum taken from Eurocode 8, using a FFT algorithm. The variables used to characterize the response are: Amplitude of the complex-valued frequency-response function, acceleration response spectra and the integral of velocity of points located at the structure. These variables clearly indicate the importance that the factors analyzed have on the dynamic response.

\section{Keywords}

Reservoir level; Reservoir geometry; Arch dam; Dam-water-sediment-foundation system; Porous sediments; Wave propagation; Boundary Element Method.

This is the pre-peer reviewed version of the following article: Influence of reservoir geometry and conditions on the seismic response of arch dams, Soil Dynamics and Earthquake Engineering 2014; 67: 264-272, which has been published in final form at http://dx.doi.org/10.1016/j.soildyn.2014.10.008. 


\section{Introduction}

There are three main factors that affect the seismic response of an arch dam: the effects of soil-structure interaction, the spatial distribution of the seismic excitation, and all those factors that can significantly affect the field of hydrodynamic pressure in the reservoir, and therefore have an impact on the pressures distribution in the upstream face of the dam.

Water compressibility, reservoir geometry, and reservoir level are included in the third group of factors, in addition to the mechanical properties of foundation rock and the possible presence of bottom sediments in the reservoir, all of which modify the effects of the dynamic interaction between the water mass with the foundation rock and with the dam itself. The importance of some of these factors has been analyzed in different studies: [1-15].

This paper focuses on the study of the influence of reservoir levels and the presence of bottom sediment layers in the reservoir on the dynamic behavior of the dam. The reservoir level is subject to seasonal cycles and has a dual impact. First, changes in the reservoir level affect the global mass of the system. Second, these changes alter the reservoir geometry. Thus, the global dynamic behavior of the reservoir, in terms of its natural frequencies and the amplifications of corresponding seismic response, is clearly subject to water height in the reservoir, and this effect can be seen in the results obtained of the seismic response. Previous studies have recognized this effect, however there are only a limited number of them that analyze the role of the reservoir level in cases other than those which considered completely empty or completely full reservoir conditions. Among the many studies that investigate this phenomenon noteworthy are experimental studies by Dabre, Smet, \& Fraemer [16], and Proulx, Paultre, Rheault, \& Robert [17] who monitored the dynamic behavior of large arch dams during different months of years under a range of water reservoir levels. These authors conclude that the dynamic behavior of the dam is strongly influenced by reservoir levels. To the extent of the Authors' knowledge, no other study that analyzes the influence of water height in connection with the presence of bottom sediments and their properties has been carried out.

Bottom sediments can reach a degree of consolidation through depth during the sedimentation process. Thus, sediment is a medium with mechanical properties that can change with depth, and are different than those found in reservoir water. On the one hand, the presence of sediments modify the bottom geometry of the reservoir. On the other, they absorb energy from the hydrodynamic waves and therefore increase the damping in the dam-water-sedimentfoundation system. 
Depending of its degree of consolidation, sediment can be modeled as a compressible scalar material with increasing density with the depth (see e.g. [11]), or it can be modeled as a porous elastic saturated material whose skeleton has taken on some type of elastic capacity (the sediment can transmit shear waves). This study follows earlier research [4, 6, 18, 19, 20, 11] and assumes that the dynamic behavior of sediment is similar to that of the porous elastic saturated or quasi-saturated material in accordance with the Biot formulation [21]. All of these studies conclude that compressibility plays a role in how bottom sediments can significantly modify global dynamic behavior, especially in the case of partially saturated sediments.

Presented results are then used to analyze the sensitivity of dam response against the reservoir level, the presence of sediments and its degree of saturation, with the aim of emphasizing important differences in the dynamic response. Three different variables have been chosen to characterize the response in different points of the rock foundation and the dam crest: the amplitude of the acceleration frequency-response functions, the acceleration response spectra, and the integral of velocity.

\section{Boundary Element Model of the dam-water-sediment-foundation system}

The Morrow Point dam (located in Black Canyon National Park, Gunnison River, Colorado, USA) has been chosen for the analysis proposed in this paper since it is well known from previous works ([2], [5], [9], [10], [20], [23]). The model assumes that the dam and foundation rock are linear, isotropic, viscoelastic materials with internal damping according to hysteretic damping model, being the latter a boundless domain when compared to the dam dimensions. The dammed up water is modeled as an inviscid, compressible fluid. The sediment is a poroelastic material that is partially saturated by water, whose dynamic behavior is represented by Biot's theory as previously noted.

Different reservoir levels have been studied with and without bottom sediments. If the height of the dam is labeled by $\mathrm{H}$, a porous bottom sediment layer with a depth equal to $\mathrm{H} / 5$ is considered in this analysis in conjunction with multiple reservoir levels given in $\mathrm{H} / 5$ increments. The study covers all eleven combinations, including the cases of full and empty reservoir conditions (Figure 1). 

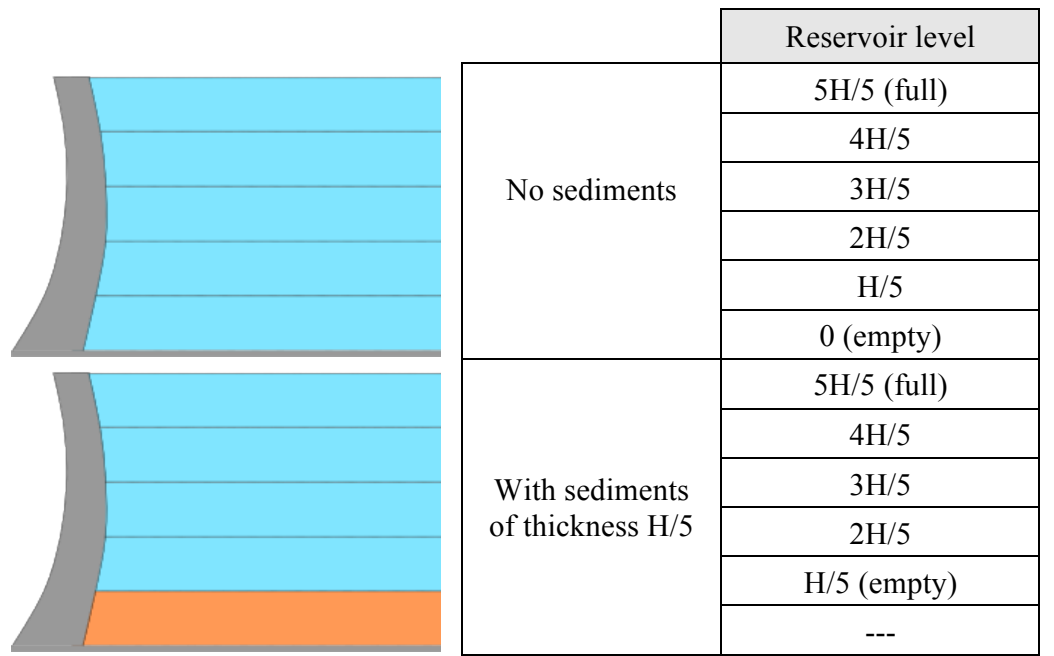

Figure 1. Problems under study with respect to presence of sediments and reservoir water level.

The media involved in this model have the following properties: The dam concrete has density $\rho_{\mathrm{d}}=2481.50 \mathrm{~kg} / \mathrm{m} 3$, Poisson's ratio $v_{\mathrm{d}}=0.2$, Shear Modulus $\mu_{\mathrm{d}}=11500 \mathrm{MPa}$, and an internal damping factor $\xi_{\mathrm{d}}=0.05$. The foundation rock has a density of $\rho_{\mathrm{s}}=2641.65 \mathrm{~kg} / \mathrm{m} 3$, and the same Shear Modulus, Poisson's ratio and internal damping factor of the dam concrete. The pressure-wave velocity of reservoir water is assumed to be $c_{w}=1438 \mathrm{~m} / \mathrm{s}$ and density $\rho_{\mathrm{w}}$ $=1000 \mathrm{~kg} / \mathrm{m} 3$. Bottom sediment is a two-phase porous material and has the same properties used by Bougacha \& Tassoulas [6] and Domínguez, Gallego, \& Japón [18] in their twodimensional studies of seismic response of gravity dams and adopted by Maeso, Aznárez, \& Domínguez [20] in their three dimensional studies of arch dams: porosity $\phi=0.6$, shear modulus of the solid skeleton $\mu_{\mathrm{s}}=7.7037 \mathrm{MPa}$, Poisson's ratio $v_{\mathrm{s}}=0.35$, internal damping factor $\xi_{\mathrm{s}}=0.05$, solid particles density $\rho_{\mathrm{s}}=2640 \mathrm{~kg} / \mathrm{m} 3$, pore water density $\rho_{\mathrm{w}}=1000 \mathrm{~kg} / \mathrm{m}^{3}$, added density $\rho_{\mathrm{a}}=0$, bulk modulus of the fully saturated pore fluid $K_{f}=2.0736 \times 10^{9} \mathrm{~N} / \mathrm{m}^{2}$, dissipation constant $\mathrm{b}=3.5316 \times 10^{6} \mathrm{Ns} / \mathrm{m}^{4}$ (corresponding to a hydraulic conductivity $\kappa=10^{-3}$ $\mathrm{m} / \mathrm{s}$ ). The bulk modulus, when sediment is partially saturated, has been calculated by using the following equation presented by Verruijt [22]:

$$
\frac{1}{K_{f}^{\prime}}=\frac{1}{K_{f}}+\frac{1-s}{p_{0}}
$$

where $K_{f}^{\prime}$ is the pore fluid compressibility under partially saturated conditions for a degree of saturation $s$, and $p_{0}$ is the hydrostatic pressure. Hydrostatic pressure depends on the reservoir level, and in this paper it is calculated as the mean depth of the bottom sediment layer. Based on this data, Biot's constants are easily obtained from the expressions $Q^{\prime}=(1-\phi) K_{f}^{\prime}$ and 
$R^{\prime}=\phi K_{f}^{\prime}$. A summary of the $K_{f}^{\prime}$ values are given in Table 1 for the five degrees of saturation $(99.8 \%, 99.6 \%, 99.4,99.2 \%, 99.0 \%)$ and reservoir levels under study. Full saturation $(s=100 \%)$ is not studied because earlier works (see Maeso, Aznárez, \& Domínguez [20]) showed that differences in the dam response are negligible with respect to cases where sediments are absent. On the contrary, partially saturated conditions $(s<100 \%)$ of sediment have a significant impact on the dynamic behavior of the system. The high level of uncertainty regarding the actual degree of saturation adopted by the bottom sediments of the reservoir justifies the study of a saturation range with the aim of understanding how this factor influences the behavior of the boundary. The $99.0 \%$ to $99.8 \%$ range was chosen for two reasons. First, it is consistent with experimental studies on the degree of saturation of sediment in real settings (Cheng [4]). Second, the greatest variability of P1 wave velocity in the sediment occurs in this range (Figure 2).

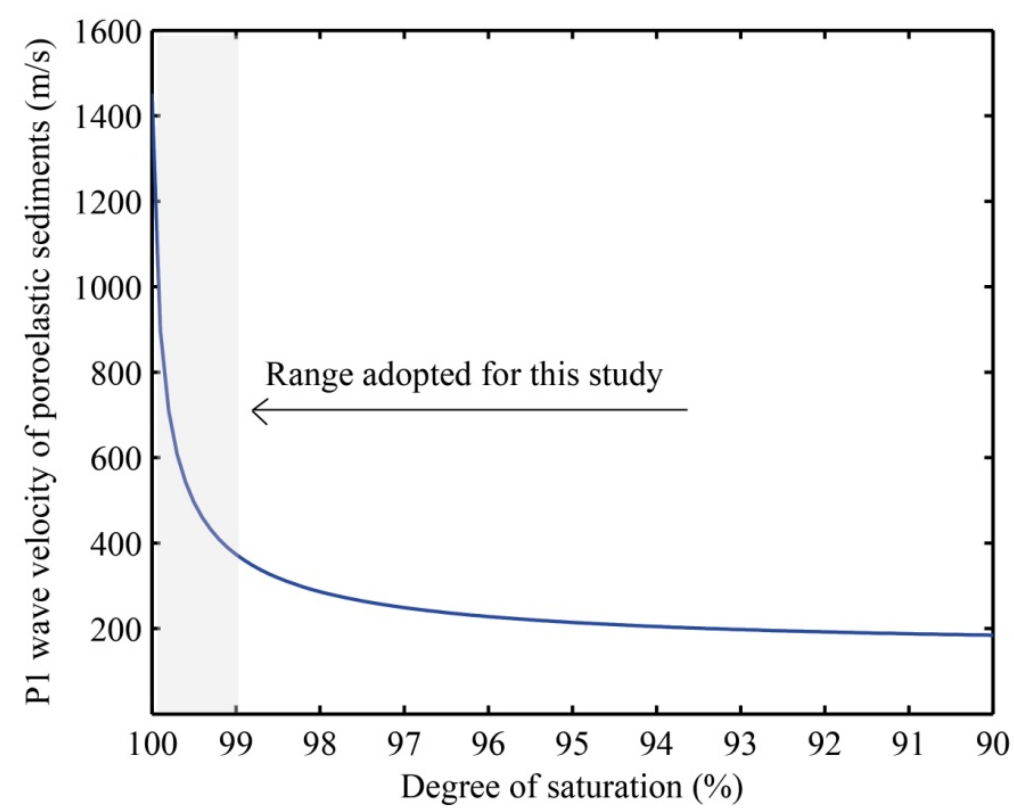

Figure 2. P1 wave velocity of porous elastic sediments versus degree of saturation.

\begin{tabular}{|c|c|c|c|c|c|c|}
\hline $\begin{array}{c}\text { Water above } \\
\text { sediment }\end{array}$ & $\mathrm{s}=99.8 \%$ & $\mathrm{~s}=99.6 \%$ & $\mathrm{~s}=99.5 \%$ & $\mathrm{~s}=99.4 \%$ & $\mathrm{~s}=99.2 \%$ & $\mathrm{~s}=99.0 \%$ \\
\hline 0 & $6.72663 \mathrm{e} 07$ & $3.41876 \mathrm{e} 07$ & $2.74406 \mathrm{e} 07$ & $2.29177 \mathrm{e} 07$ & $1.72359 \mathrm{e} 07$ & $1.38117 \mathrm{e} 07$ \\
\hline $\mathrm{H} / 5$ & $1.89501 \mathrm{e} 08$ & $9.92872 \mathrm{e} 07$ & $8.01978 \mathrm{e} 07$ & $6.72650 \mathrm{e} 07$ & $5.08613 \mathrm{e} 07$ & $4.08896 \mathrm{e} 07$ \\
\hline $2 \mathrm{H} / 5$ & $2.97697 \mathrm{e} 08$ & $1.60359 \mathrm{e} 08$ & $1.30303 \mathrm{e} 08$ & $1.09735 \mathrm{e} 08$ & $8.34046 \mathrm{e} 07$ & $6.72648 \mathrm{e} 07$ \\
\hline $3 \mathrm{H} / 5$ & $3.94141 \mathrm{e} 08$ & $2.17766 \mathrm{e} 08$ & $1.77951 \mathrm{e} 08$ & $1.50444 \mathrm{e} 08$ & $1.14917 \mathrm{e} 08$ & $9.29643 \mathrm{e} 07$ \\
\hline $4 \mathrm{H} / 5$ & $4.80649 \mathrm{e} 08$ & $2.71829 \mathrm{e} 08$ & $2.23318 \mathrm{e} 08$ & $1.89500 \mathrm{e} 08$ & $1.45448 \mathrm{e} 08$ & $1.18014 \mathrm{e} 08$ \\
\hline
\end{tabular}

Table 1. Pore fluid compressibility $K_{f}^{\prime}\left(\mathrm{N} / \mathrm{m}^{2}\right)$ of poroelastic sediment for different reservoir levels and degrees of saturation. 
A sketch of the problem under study is given in Figure 3. To address it, a numerical model based on the Boundary Element Method is used. This model is described by the authors in previous studies, such as in [11] or [20]. All the regions of the dam-reservoir-sedimentfoundation system are represented by boundary integral equations discretized into boundary elements, taking into account their specific characteristics and the interaction between them by using existing compatibility and equilibrium relationships on the variables defined for each domain in the nodes of the contact surfaces.

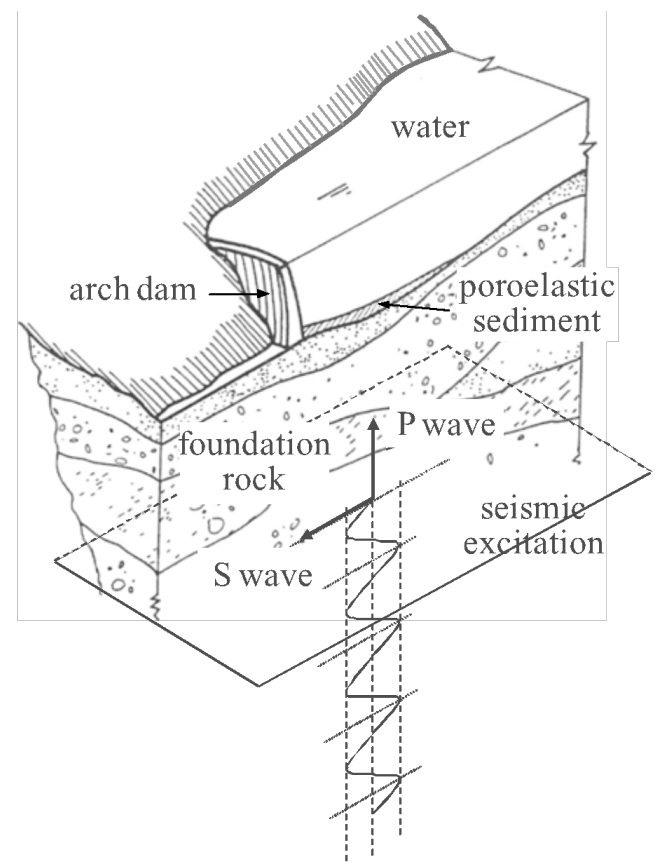

Figure 3. Dam-water-sediment-foundation system.

The boundary element discretizations used in the study are shown in Figure 4. Only one half of the complete geometry is discretized because it is assumed that the dam-reservoirsediment-foundation system is divided by a plane of symmetry. Nine-node quadratic quadrilateral elements and six-node quadratic triangular elements are used in the model, where a parabolic approximation is utilized not only in the geometry but also in the boundary variables. The foundation rock free surface discretization extends to a distance equal to 2.5 times the dam height, increasing the size of the elements as the distance from the area of interest increases. No discretization is needed on the water free surface since the half-space fundamental solution is used for this region. The size of the elements is determined by the wavelength in each material (except in the foundation rock free surface as has been previously mentioned). Preliminary numerical proofs carried out show that this boundary element mesh assures a good representation of the coupled system analyzed.

The study was carried out using two different models for the reservoir shape in an area far 
from the dam. The first one is a closed reservoir model (Figure 4a) and represents the reservoir geometry when water depth is very shallow far from the dam. The second one is an open reservoir model (Figure 4b) and is characterized by an unbounded water domain with a uniform geometry, which can be modeled by introducing a transversal absorbing boundary to the canyon which forces a relationship between the hydrodynamic pressure and its flux analog from the solution for an infinite water channel. This unbounded model is used by Hall \& Chopra [2] and Fok \& Chopra [5] with finite element models and by Medina \& Domínguez [24], Domínguez \& Maeso [9] and Aznárez, Maeso, \& Domínguez [11] with boundary elements. Geometric conditions from the actual problem determine which reservoir model to use, that is, either the closed reservoir model (finite) or open reservoir model (infinite). Although the dam geometry at Morrow Point for our study has open reservoir features, both models (and their results) are presented in order to compare the responses in each case.

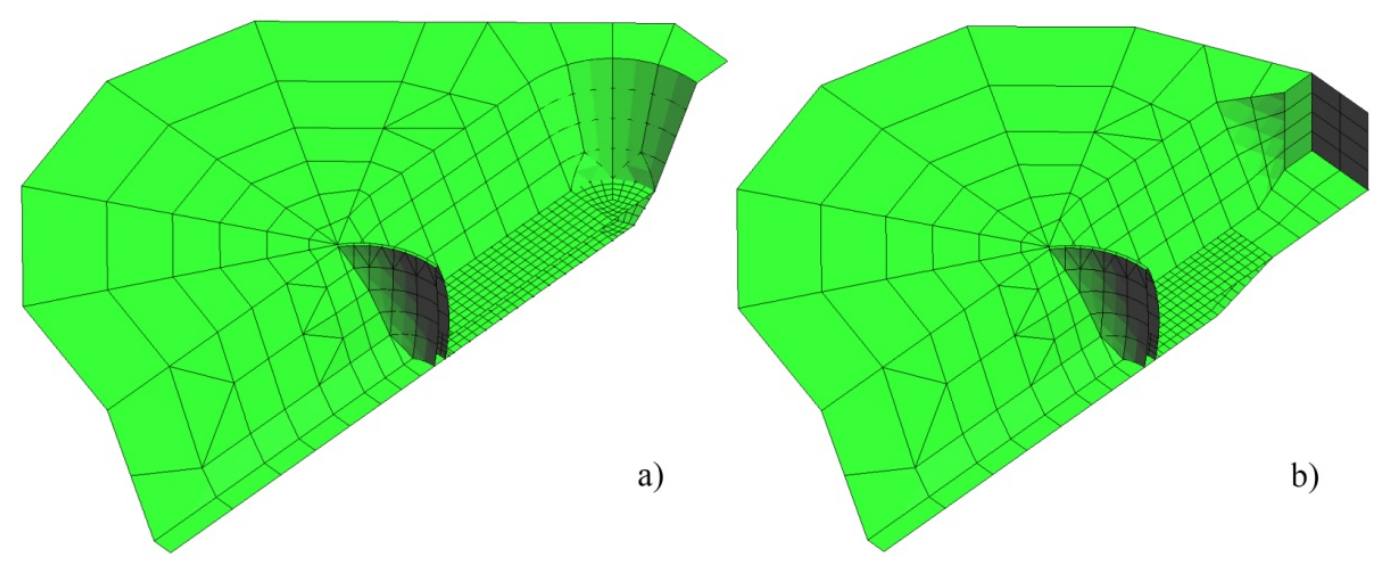

Figure 4. Boundary element discretizations: a) Closed reservoir model, b) open reservoir model

The maximum height and width of the dam discretization are $142 \mathrm{~m}$ and $190 \mathrm{~m}$, respectively. The longitude of the upstream sediment stratum are $324 \mathrm{~m}$ and $168 \mathrm{~m}$ for closed and open reservoir, respectively.

Seismic excitation is modeled using polarized plane harmonic $\mathrm{P}$ and $\mathrm{S}$ waves according to the " $x$ " and " $y$ " axes that vertically impinge on the dam site from infinity (Figure 5), the coordinate origin is located at the midpoint of the dam crest with the $\mathrm{x}$ axis along the canyon axis and the $y-z$ plane tangent to the dam midsurface). The Boundary Elements equations are written in terms of the diffracted field, so that the radiation conditions are automatically satisfied, allowing the boundary element mesh only extends to a certain distance from the dam, leaving the foundation rock mesh open from that point as shown in Figure 4. 


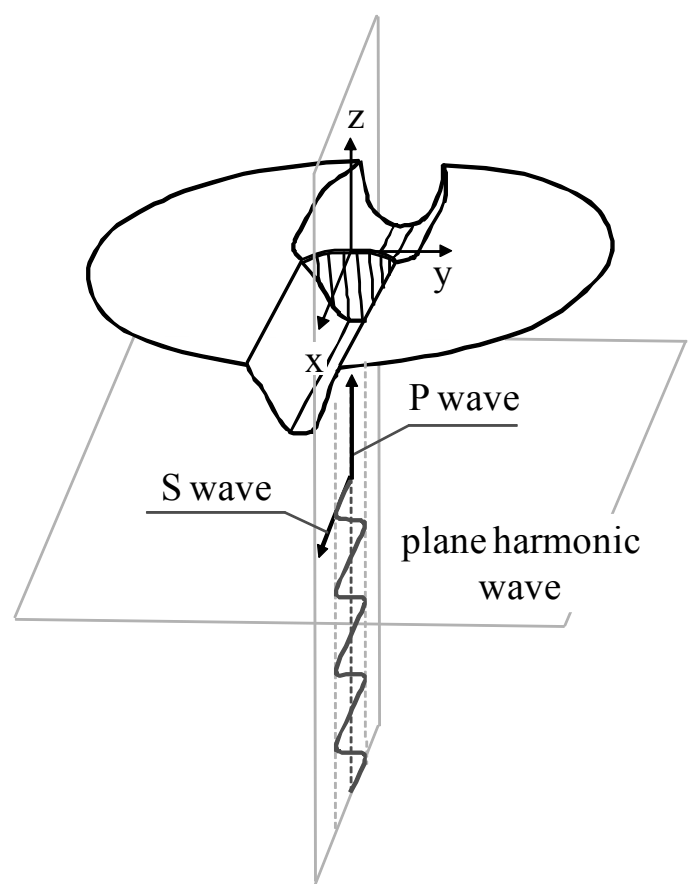

Figure 5. Vertical seismic excitation contained in the y-z plane of the model.

\section{Response quantities represented. Seismic input motion}

Dam response is represented using three dynamic variables: the amplitudes of the acceleration frequency-response functions, acceleration response spectra, and the integral of velocity at a number of points along the rock foundation and the dam crest. These results are shown in Section 3 .

Time-history responses are those associated with a compatible synthetic earthquake with Type 1 design elastic response spectra for Ground Type A and design ground acceleration $0.35 \mathrm{~g}$, consistent with those indicated in Eurocode 8 (EN 1998-1) [25] that has been obtained using SIMQKE software [26]. The seismic ground acceleration (far-field acceleration) timehistories obtained for the horizontal and vertical components, once the base line has been corrected using the procedure described by Kausel and Ushijima [27], are shown in Figure 6 (the duration of the record is $30 \mathrm{~s}$ for both component of ground motion).

Time responses are obtained from the horizontal and vertical accelerograms that are produced by the scattering of an $\mathrm{S}$ and $\mathrm{P}$ wave, respectively. Additional details concerning the generation and treatment of the accelerograms are available in [28].

The frequency response functions of the system to impinging waves are calculated using the Boundary Element model previously mentioned. Based on these results and the ground motion record generated, the response in the time domain will be using the Fast Fourier Transform (FFT) algorithm. 

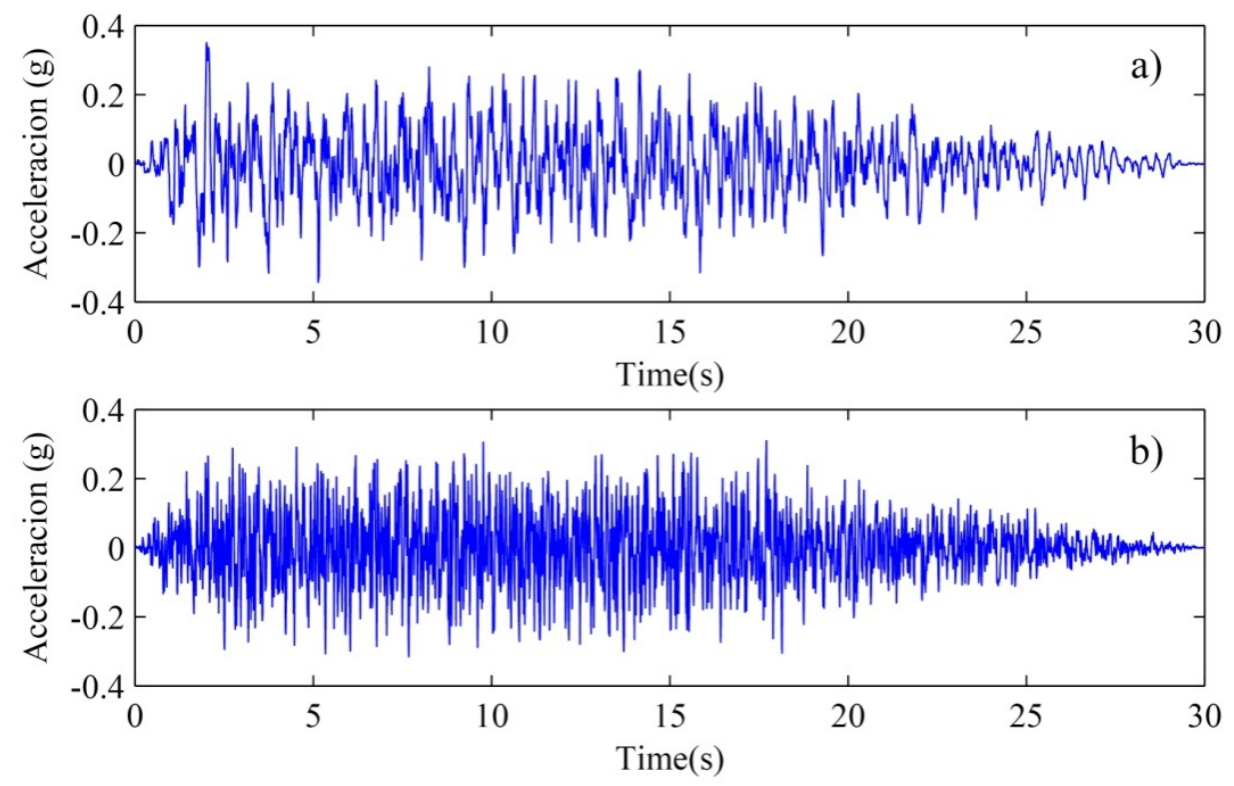

Figure 6. Time histories of seismic input far-field accelerations: horizontal-x (a) and vertical-z (b).

\section{Analysis of results}

\subsection{Amplitude of the complex-valued frequency-response function at the dam crest}

Figures 7 and 8 show the amplitude of the complex-valued frequency-response function in the " $\mathrm{x}$ " direction obtained at the point located at the dam crest in the plane of symmetry under different reservoir conditions, for vertical time harmonic plane $\mathrm{S}$ and $\mathrm{P}$ waves, respectively. In each transfer function, the response is expressed by means of a dimensionless variable that represents the amplitude of the acceleration due to an excitation that would produce unit acceleration at the far-field free surface. Each one of the figures includes five graphs that show the five different reservoir levels (see figure 1). Solid lines are used for the open model, while dashed lines represent the closed model. Blue curves represent results where there are no bottom sediments; those in red represent situations for quasi-saturated sediment layers of width $\mathrm{H} / 5$ and $99.5 \%$ (intermediate) degree of saturation (see table 1). In each case the amplitude of the acceleration is plotted versus the angular frequency ( $\mathrm{rad} / \mathrm{s})$ for a significant range. 

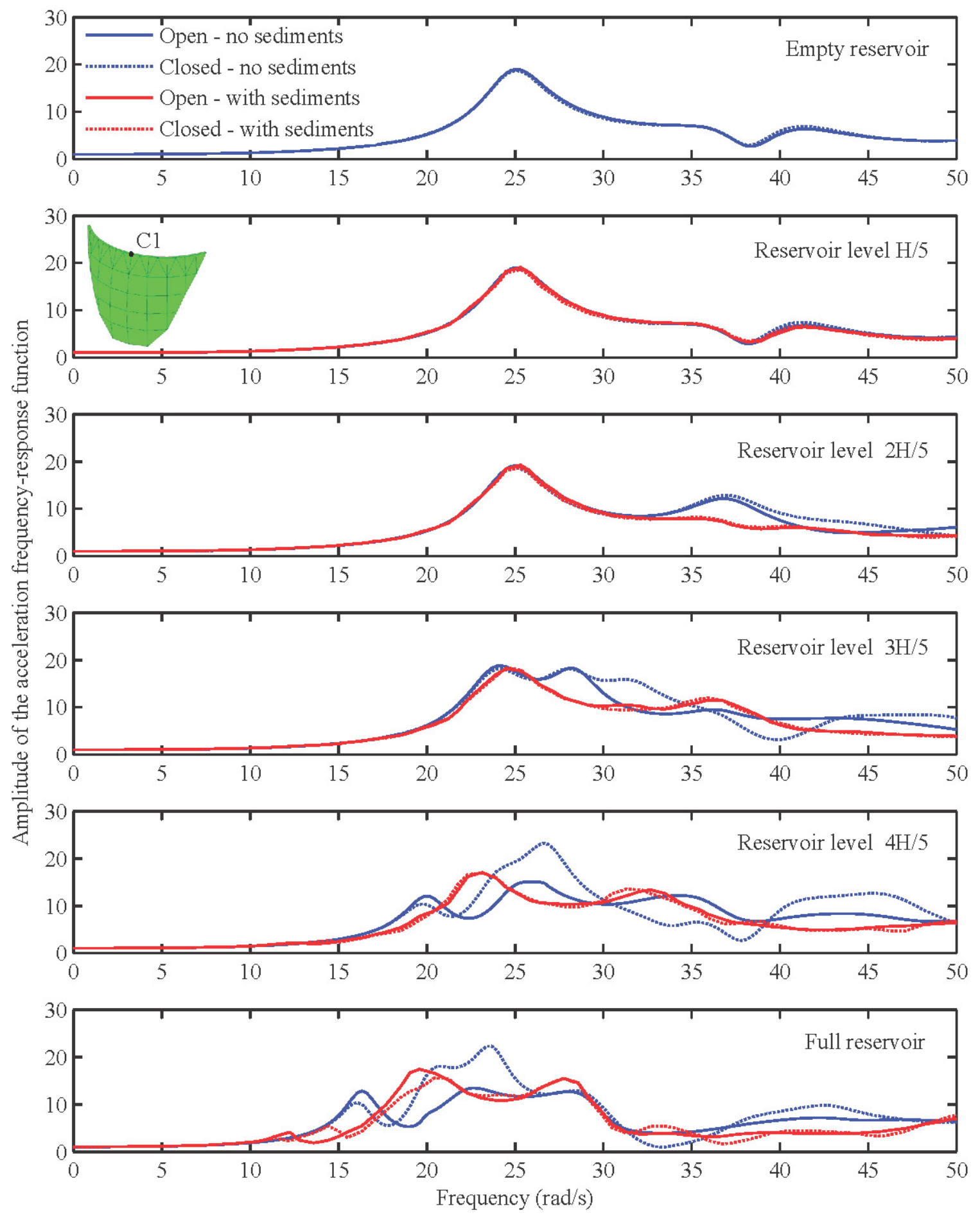

Figure 7. Amplitude of the acceleration frequency-response function. "x" direction. S-wave. Point $\mathrm{C} 1$. 

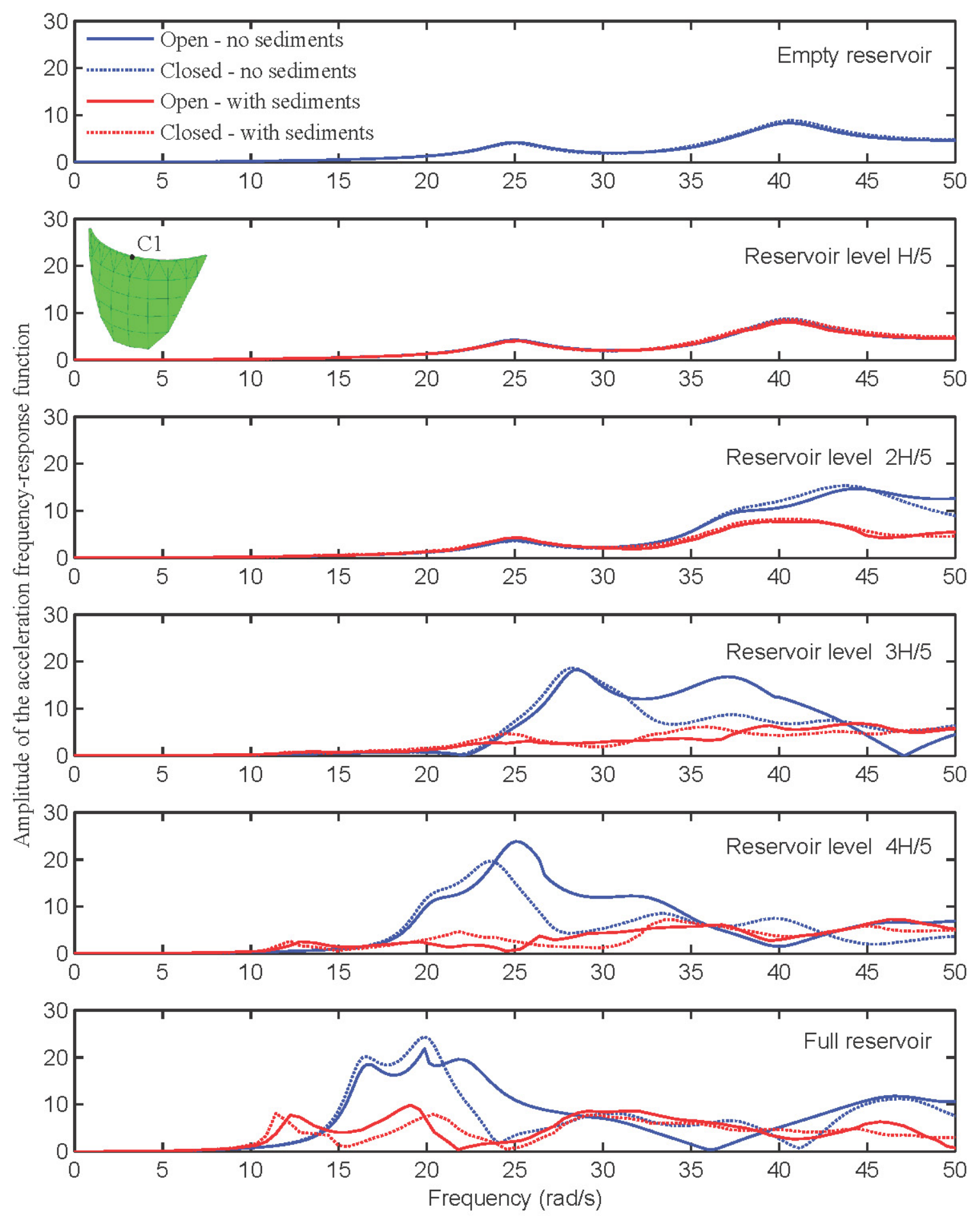

Figure 8. Amplitude of the acceleration frequency-response function. "x" direction. P-wave. Point $\mathrm{C} 1$.

As expected, changes in the reservoir level produce substantial differences in the dynamic response of the dam over the frequency range analyzed. It is well known that the gradual increase in water level produces a reduction in the natural frequency of the coupled system and at the same time modifies the position of the other resonance peaks, as well as the relative importance of the amplifications at each one.

Response sensitivity to the presence of sediments is more evident for the incident $\mathrm{P}$ wave than 
for the incident $\mathrm{S}$ wave. The bottom sediment layer clearly has a damping effect that is more noticeable as the reservoir water level increases.

When there are no bottom sediments (blue curves), the distant reservoir geometry produces substantial changes in the dam response and both the open or closed reservoir model has the same relevance in the dynamic response for the two types of waves used. On the contrary, if bottom sediments are present, the reservoir geometry far from the dam has a limited effect on the dynamic response for both waves. Therefore, reservoir level and bottom sediments are determining factors in the dynamic behavior of the coupled system. This conclusion is especially evident in the P-wave excitation case. It is seem logical considering that this type of incident wave leads to increased levels of excitation in the water mass, in contrast to what happens for the S-wave, (there is no shear stress in the water-solid interfaces) and also excites the natural frequencies of the water layer related to the one-dimensional problem of vertical propagation.

In general, as it is well known, the magnitude of the response increases with the amount of water in the reservoir. However, in the open model (S-waves excitation case) it seems that a reduction of the response is observed as the quantity of water in the reservoir increases, starting with level $3 \mathrm{H} / 5$. This may be explained by the greater dissipation of energy due to the hydrodynamic wave radiation in the reservoir closing boundary as water level increases.

Finally, it is noteworthy that either completely full or completely empty reservoir conditions do not necessarily generate the worst case scenario from the point of view of the amplifications of the obtained response.

\subsection{Acceleration response spectra along the dam abutment}

The study in the previous subsection is now extended in order to assess how the reservoir conditions affect the seismic response along the dam abutment. For the sake of brevity, only the results for the open model will be shown. Those corresponding to the closed model are similar and have no impact on the conclusions reported below.

Three points are chosen (E1, E2 and E3, Figures 9 to 14), all located on the dam-foundation rock interface at different elevations: E1 is at the height of the dam crest, E2 is approximately at one half the height of the dam and E3 is at the bottom of the canyon. Acceleration response spectra along the canyon axis direction ("x") are given for each one of these points for incident $\mathrm{S}$ and P-waves. The shaded area in each graph represents the variability of the response for the 18 different analyzed situations which correspond to three reservoir levels (full, $4 \mathrm{H} / 5$ and $3 \mathrm{H} / 5$ ) combined with six situations related to the presence of sediments: the 
absence of it or a sediment layer of width $\mathrm{H} / 5$ with five different degrees of saturation (99.8\%, 99.6\%, 99.4\%, 99.2\% and 99.0\%) (see Figure 1). The 3D canyon free field motion, which is shown by the corresponding curves of acceleration response spectra for the point considered in each case, is included to aid in the analysis of the influence that the local effect produced by the actual geometry of the canyon. Two other curves are also included: Deconvolution of the horizontal elastic response spectrum, at the point depth analyzed in each case (only for a wave field produced by vertically propagating $\mathrm{S}$ waves), and the design spectrum at free surface representative of ground excitation. All these acceleration response spectra were calculated using a damping factor $\xi=5 \%$.

It is very interesting to explore how the effects of soil-structure interaction are relevant in the response of the system, that is to say, the effects due to the presence of dam on the acceleration response spectra in these points (which are also points belonging to foundation rock) corresponding to the canyon free field motion. Along the same lines, it would be interesting to know to what extent do reservoir conditions (reservoir level, presence of sediments and degree of saturation) influence the response spectra in these points. Conclusions drawn from obtained results depend on which type of incident wave is analyzed.

The analysis of the acceleration response spectra caused by the component of ground motion along the canyon axis (S waves) (Figure 9 for point E1; Figure 10 for point E2 and Figure 11 for point E3) show that, in this case, the dam has little impact on the response along the dam abutment. In addition, the response spectra hardly depend at all on the reservoir level and bottom sediments (or absence thereof). In this case, therefore, acceleration response spectra are reasonably well represented by those corresponding to the wave field scattering due to the canyon exclusively (canyon free field motion). It is also clear that the spectra are invariably greater to those corresponding to the deconvolution of the design spectra for a uniform semispace. That is, the local effect caused by the irregularity of the canyon causes greater accelerations in the abutment than those that would be obtained in the half-space free field solution at the same elevation.

An analysis of the acceleration response spectra along the axis canyon caused by the vertical component of ground motion (P wave with vertical incidence) (Figure 12 for point E1, Figure 13 for point E2 and Figure 14 for point E3) is now undertaken. Given the three-dimensional character of the problem, even in the absence of the dam, the response of the foundation rock to $\mathrm{P}$-waves with vertical incidence presents displacements in $\mathrm{x}$-direction. The results reveal that the presence of the dam and the water reservoir increase the values of the registered 
accelerations. For vertical P-waves, the presence of the arch dam causes an increase in the acceleration response spectra in the axis direction of the canyon. The difference with the response that only includes the local canyon effect is much more pronounced when the measuring point is closer to the bottom of the reservoir.

Based on the analysis performed, it can be concluded that the use of the solution of the free field problem for x-axis excitation, including the scattering wave field by the canyon, can be used as direct excitation on a more simplified model of this problem like one of those existing in the literature. This does not mean, as we shall see later on, that the precise modeling of the reservoir and its interaction with the structure are not determinant in the dynamic response of the points of the dam. The conclusion is different for vertical excitation. In this case, the response along the abutment in the upstream direction is in fact determined by the interaction effects of the coupled system.

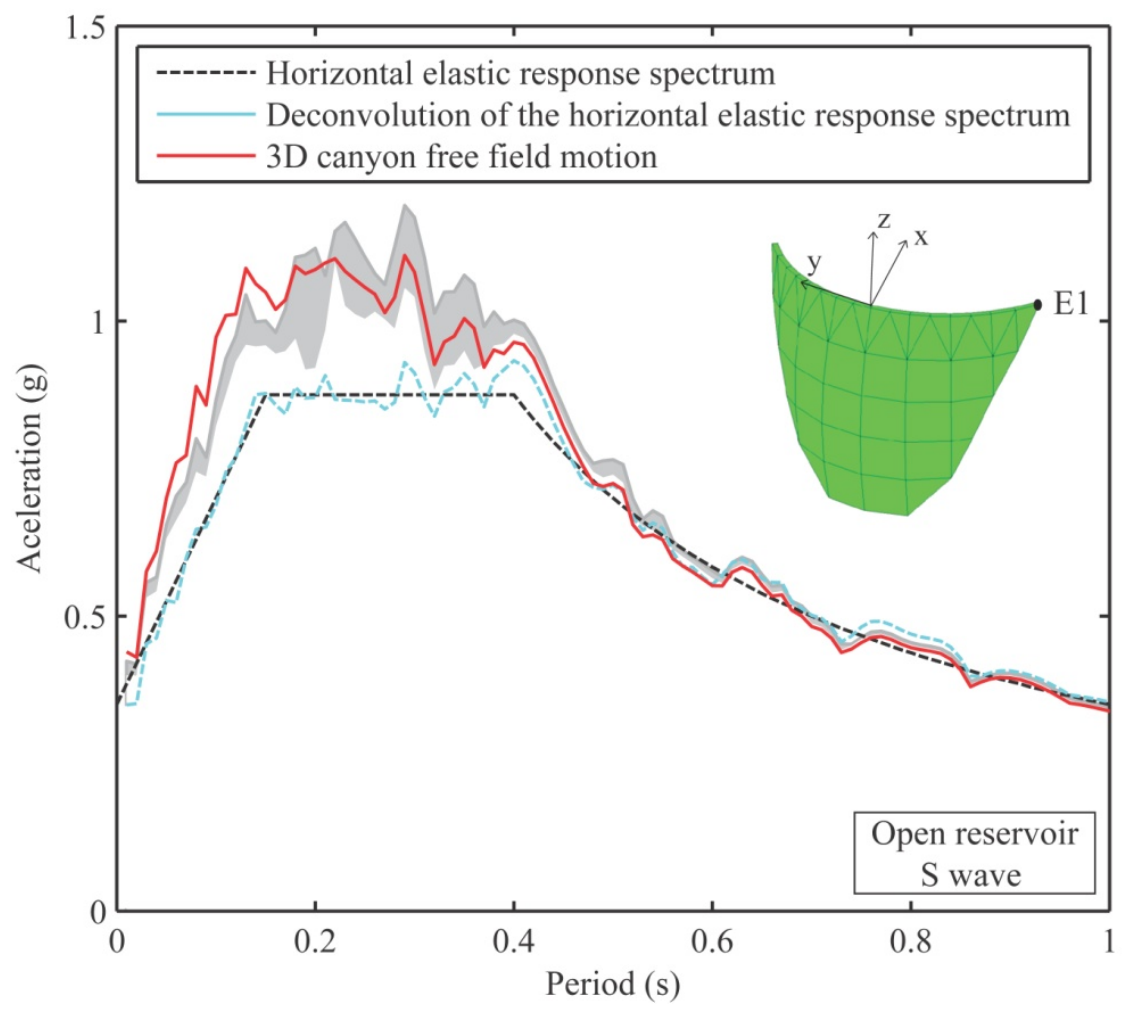

Figure 9. Pseudo-acceleration Response spectra. ' $\mathrm{x}$ ' direction. S wave. Point E1. 


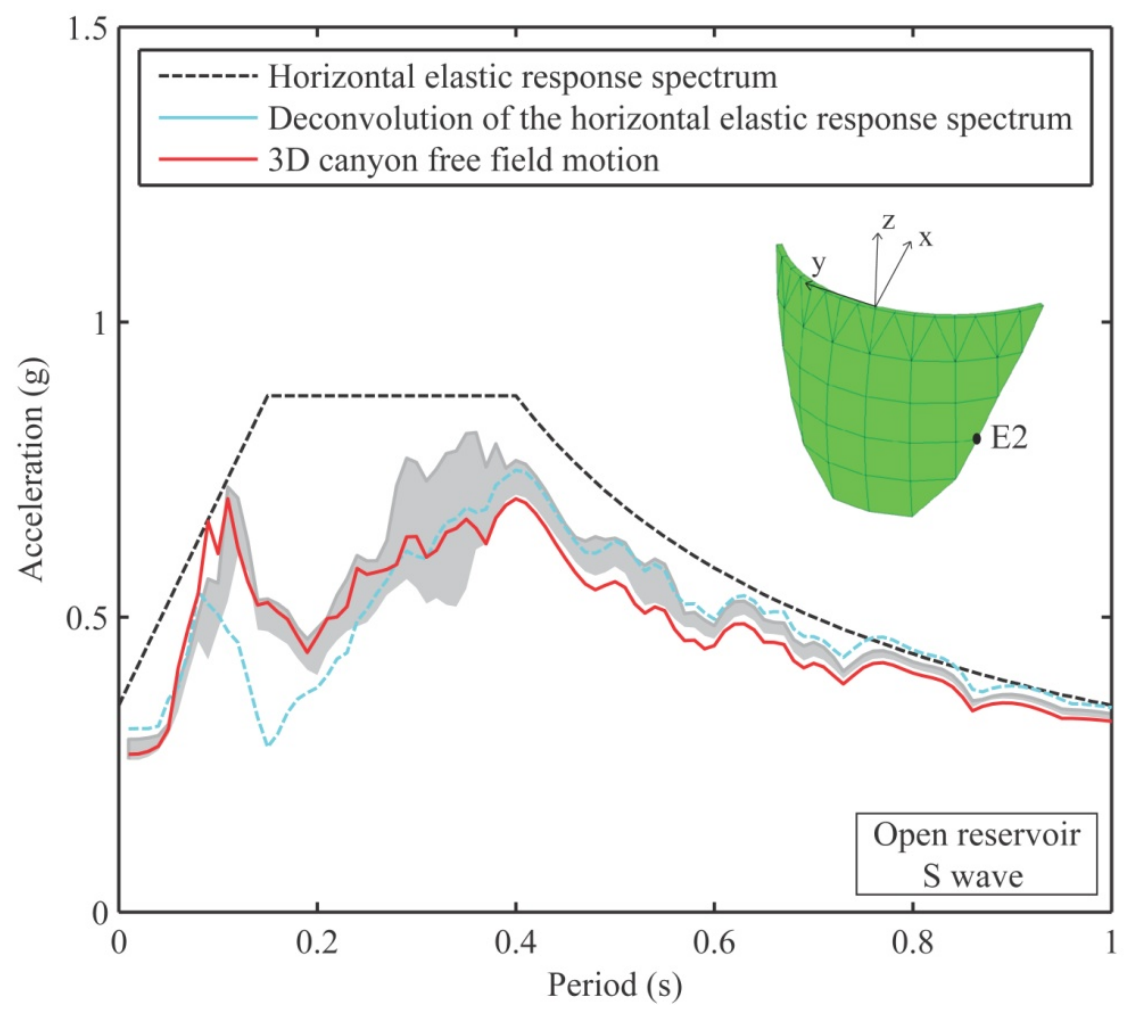

Figure 10. Pseudo-acceleration Response spectra. ' $x$ ' direction. S wave. Point E2.

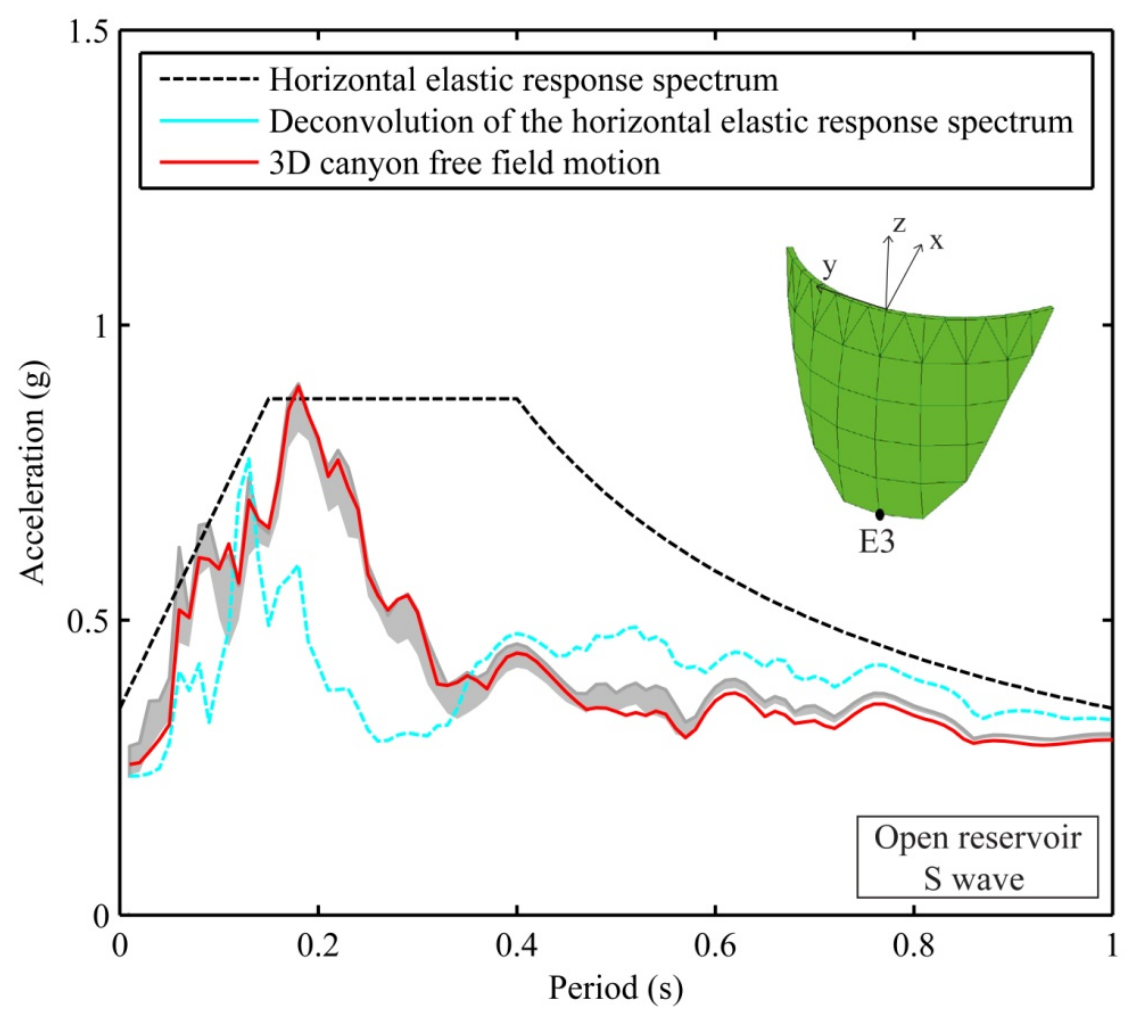

Figure 11. Pseudo-acceleration Response spectra. ' $\mathrm{x}$ ' direction. $\mathrm{S}$ wave. Point E3. 


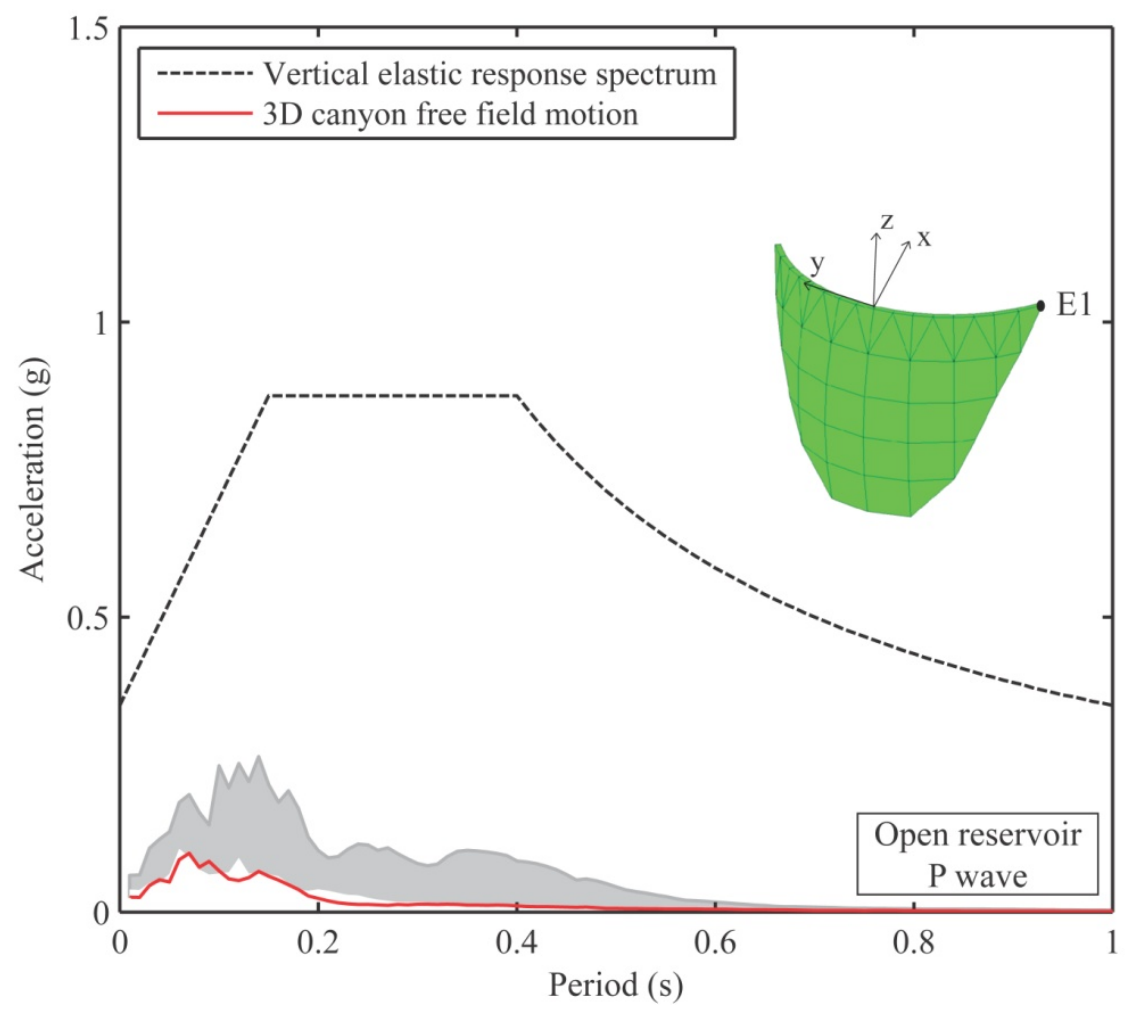

Figure 12. Pseudo-acceleration Response spectra. ' $x$ ' direction. P wave. Point E1.

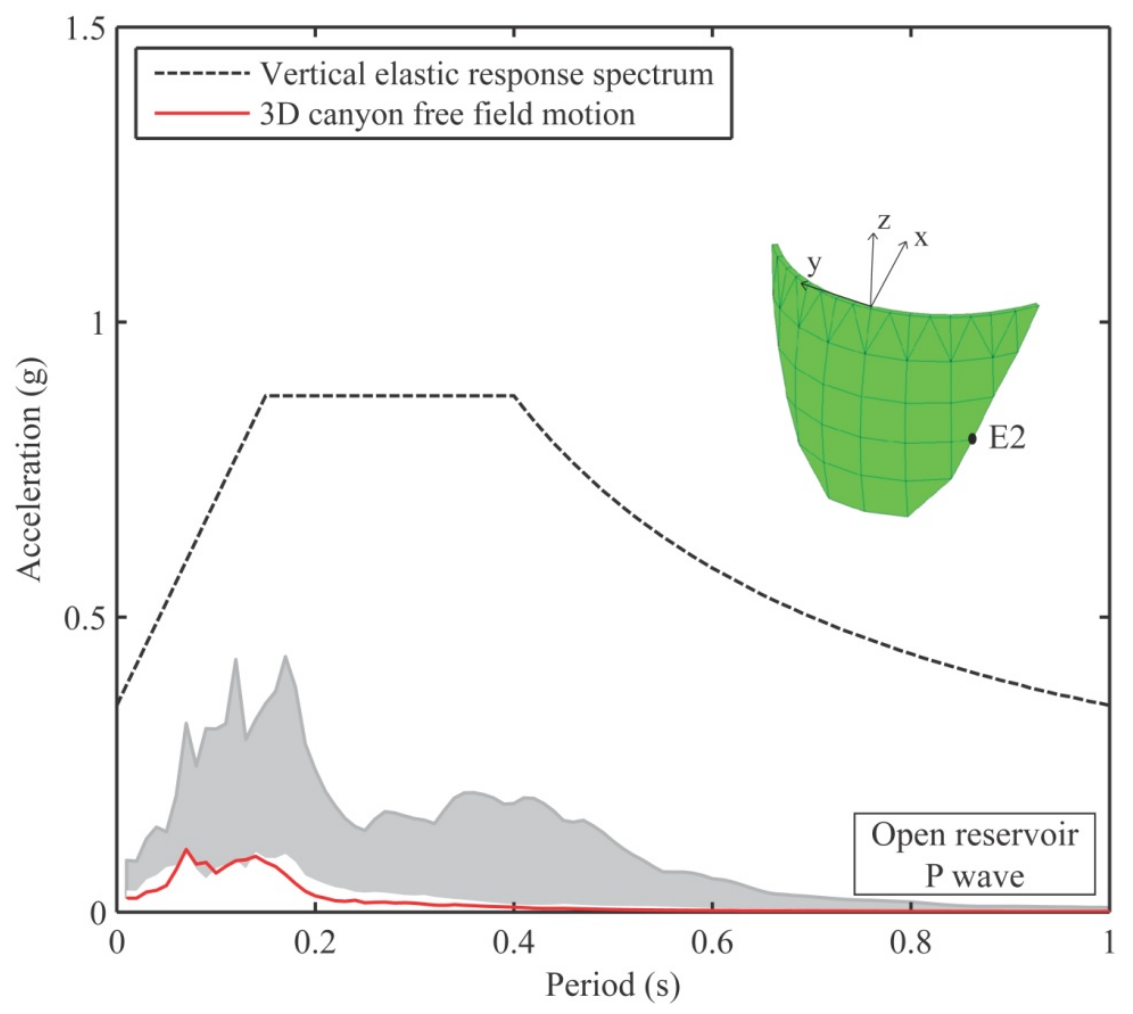

Figure 13. Pseudo-acceleration Response spectra. ' $\mathrm{x}$ ' direction. $\mathrm{P}$ wave. Point E2. 


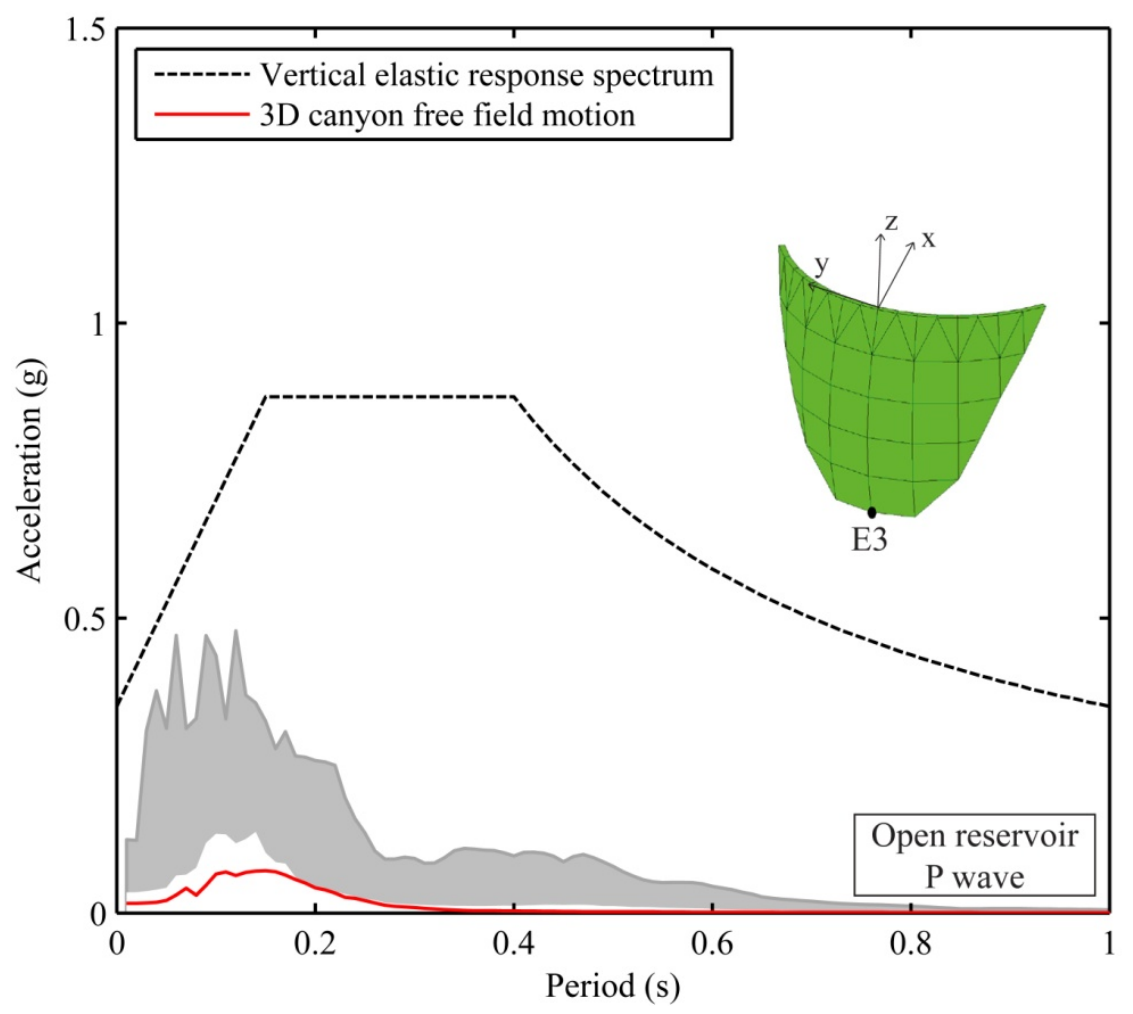

Figure 14. Pseudo-acceleration Response spectra. ' $x$ ' direction. $P$ wave. Point E3.

\subsection{Integral of squared velocity at the dam crest}

It is interesting to compare the response at points in the dam crest (match with nodes of discretization) in terms of total transmitted energy from the earthquake to the structure. Instead of being based on maximum values of acceleration responses, velocities or displacements, this variable is better represented by the integral of squared acceleration or velocity. In this paper we use the last one:

$$
I_{E}=\int_{t_{0}}^{t_{\text {end }}} v_{x}^{2}(t) d t
$$

where the interval of integration is given by the duration of the accelerogram $\left(t_{0}=0 \mathrm{~s}\right.$ and $\left.\mathrm{t}_{\text {end }}=30 \mathrm{~s}\right)$.

Results are presented in the upstream direction for the open and closed models and the Pwave (Figures 15 and 16) and S-wave (Figures 17 and 18) excitation cases. Each figure consists of eighteen curves resulting from combining three reservoir levels (full, $4 \mathrm{H} / 5$ and $3 \mathrm{H} / 5$ ) with six situations relative to the sediment layer (one corresponds to the situation with no sediments and the other five for the cases of sediments with the five different degrees of saturation used in previous sections). The shaded area in each graph represents the variability of the response for all the analyzed situations. Both responses (to $\mathrm{P}$ and $\mathrm{S}$-wave excitation) 
once again display the two effects previously commented on in the analysis of the frequency complex response functions of the system. On one hand, the increase of the response follows the quantity of reservoir water, an effect that is especially important when there are no bottom sediments. On the other, the damping effect of the response due to the presence of sediments is greater as the degree of saturation of the sediments decreases.

The behavior of the response with respect to the geometry of the reservoir upstream (open or closed) is different depending on the type of incident wave. In the case of incidence of a Pwave (Figures 15 and 16) there are considerable differences in the response, producing greater values of the response in the open model than in the closed one for a certain situation in reference to the water level and the degree of saturation of the sediments. The response is indifferent to the distant geometry of the reservoir upstream only for the full reservoir without sediments (black curves in Figures 15 and 16). In the S-wave excitation case (Figures 17 and 18) a much lower sensitivity against this factor is observed. The general tendency is smaller values of response for a specific reservoir level in the open model than in the closed one (the opposite of what happens with the P-wave). For both types of incident wave, the importance of the reservoir far geometry upstream decreases when the sediments are more unsaturated.

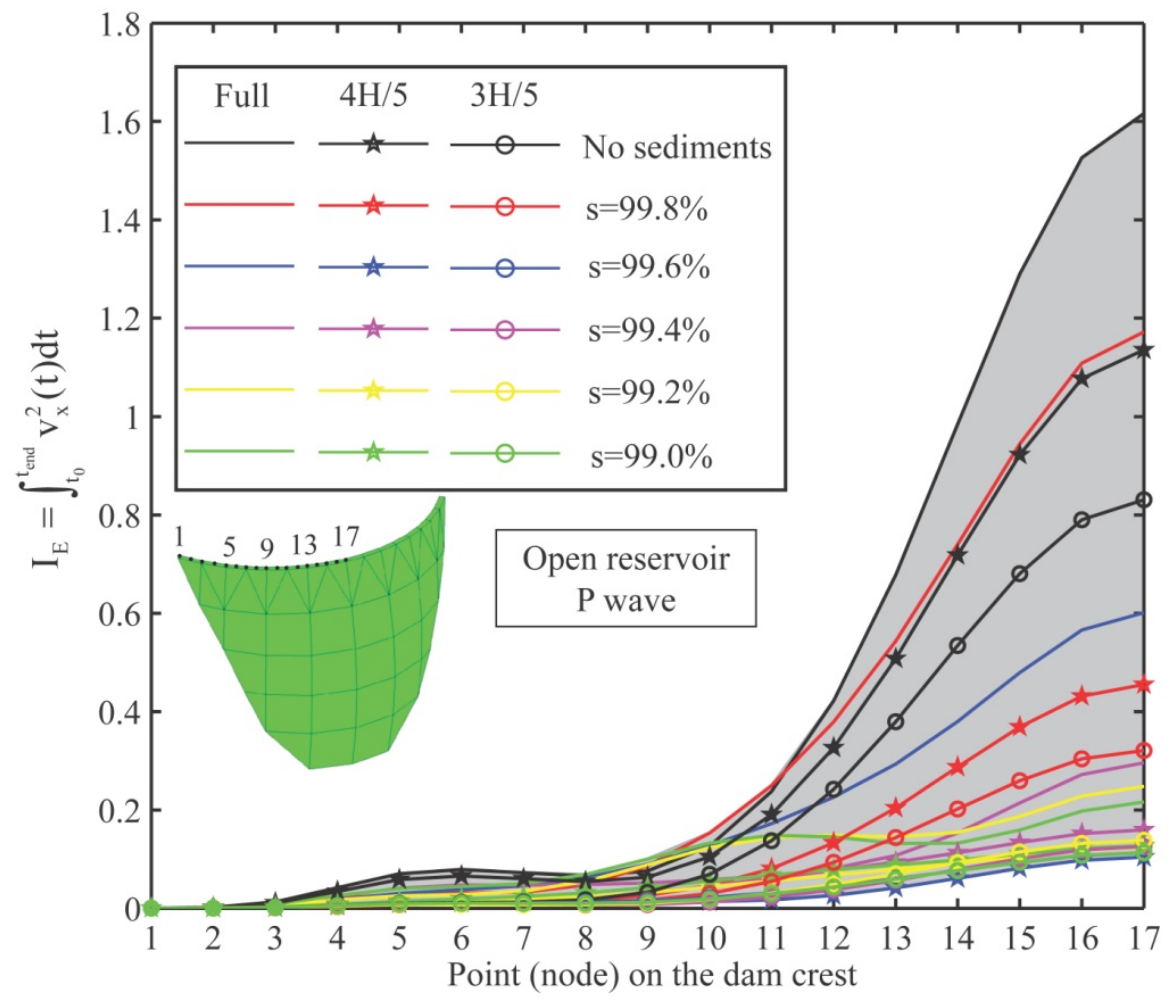

Figure 15. Integral of squared velocity along the dam crest. Open reservoir. P-wave. 


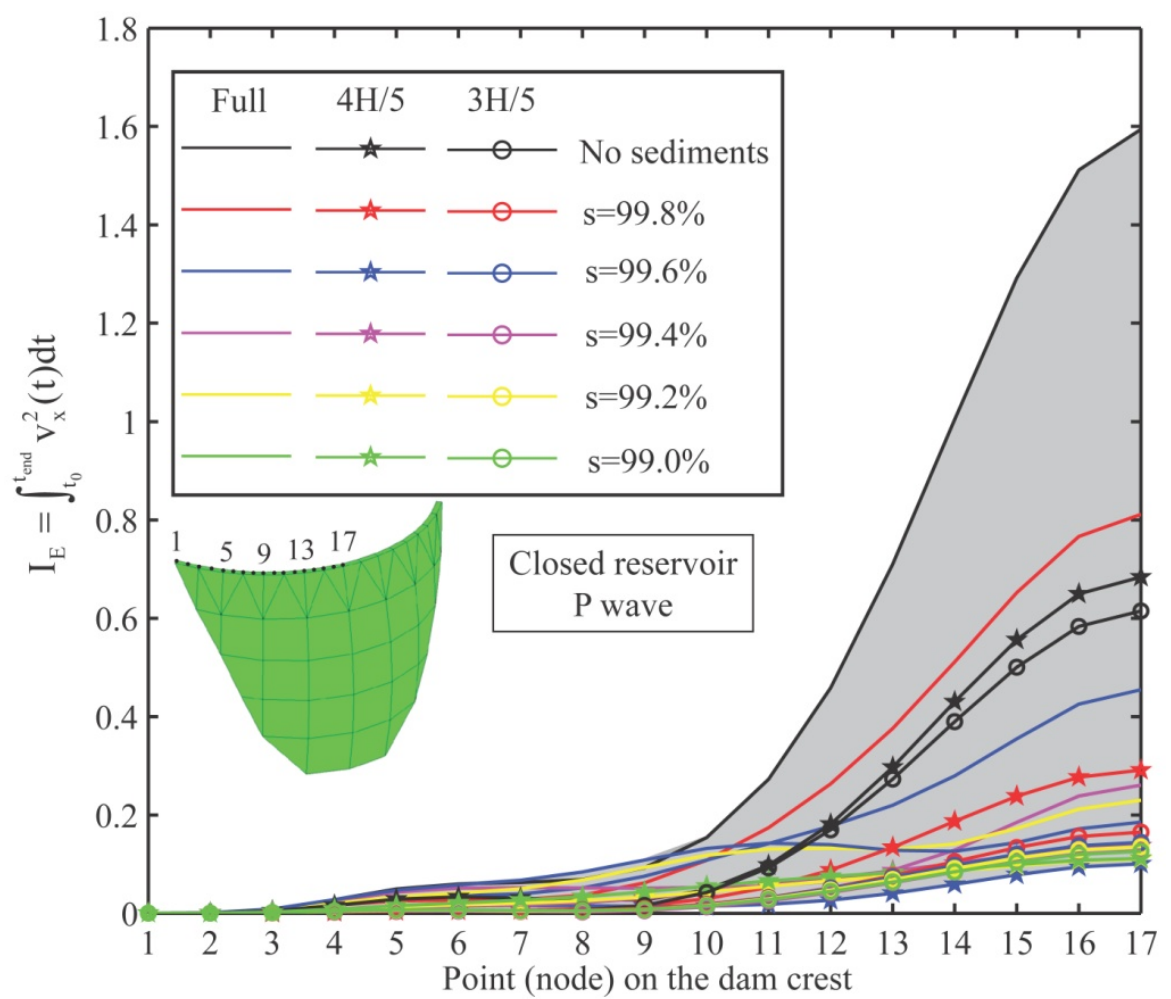

Figure 16. Integral of squared velocity along the dam crest. Closed reservoir. P-wave.

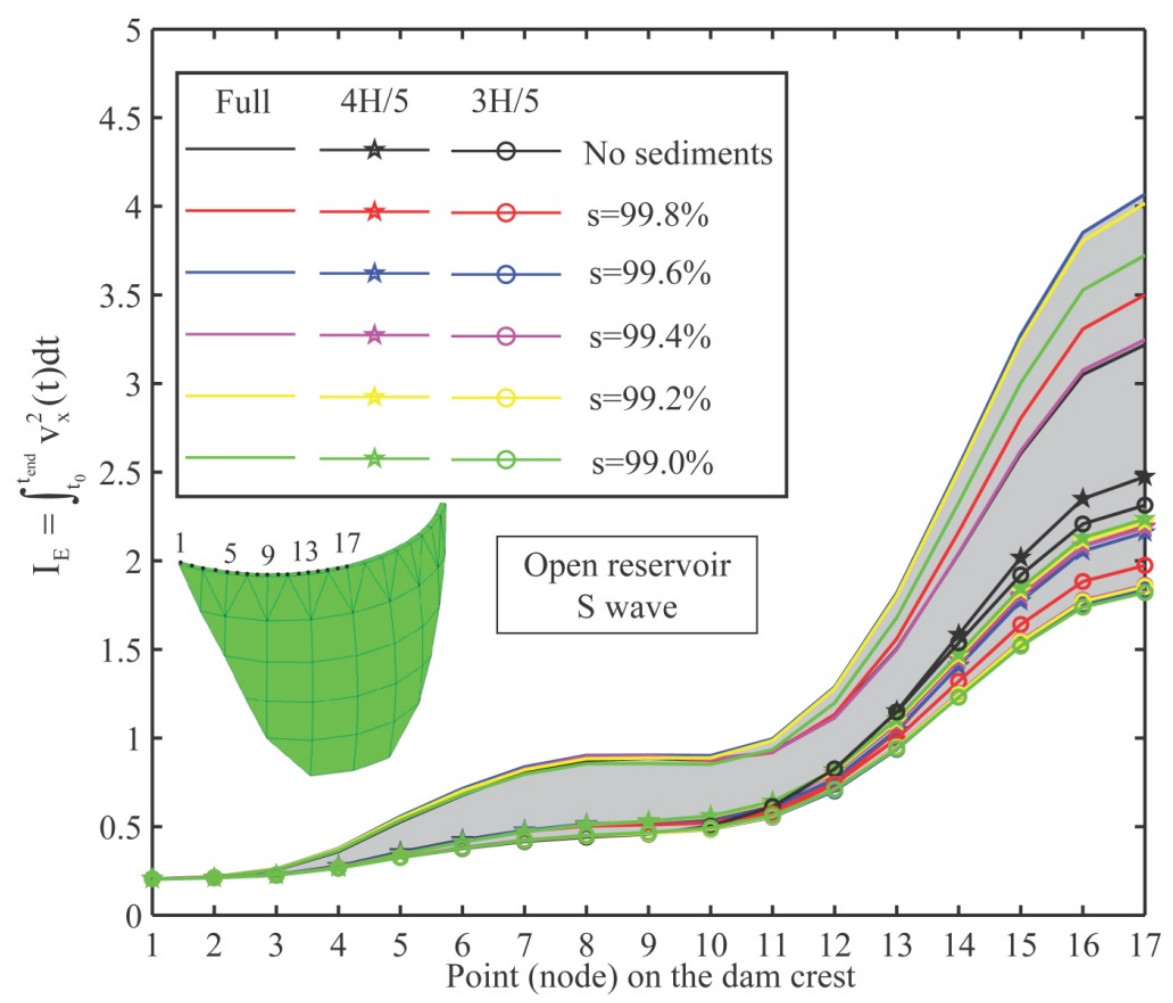

Figure 17. Integral of squared velocity along the dam crest. Open reservoir. S-wave. 


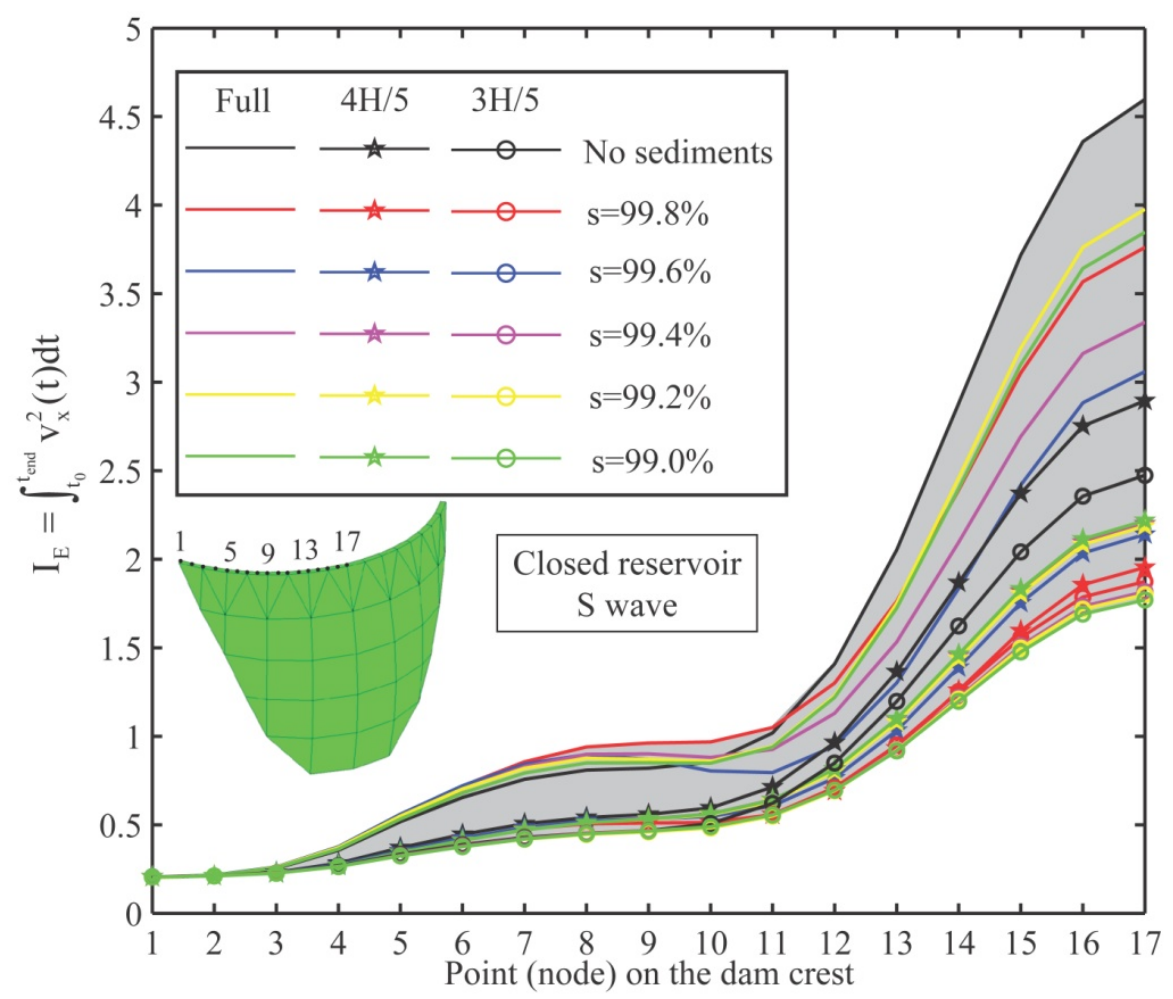

Figure18. Integral of squared velocity along the dam crest. Closed reservoir. S- wave.

\section{Conclusions}

In this paper, a study that reveals the influence of reservoir conditions on the seismic response of arch dams is presented. Specifically, upstream reservoir geometry, reservoir level and degree of saturation of bottom sediments are investigated. A Boundary Element model developed by the authors is used which allows a direct and coupled analysis of all of the involved regions: dam, foundation rock, reservoir water and bottom sediments [20]. Dam and foundation rock are modeled as viscoelastic solids, water as an inviscid compressible fluid and bottom sediment as a poroelastic material according to a Biot model. In relation to similar studies previously carried out, this paper contributes by extending the number of cases studied simultaneously on varying reservoir geometry (open or closed), the height of the reservoir levels and the degree of saturation of the bottom sediments. Five reservoir levels were studied, ranging from an empty reservoir to a completely full one, and six values for degree of saturation of the sediment in the range where compressibility, and consequently the velocity of the dominant waves, experiences the most relevant changes. A total of 18 cases covering different combinations were studied, for which the acceleration response spectra for points along the dam abutment and the integral of squared velocity throughout along the dam crest were calculated, for a synthetic seismic ground motion compatible with Eurocode 8. Based on the obtained results and classified by the response variables used, the following conclusions 
can be drawn:

1.- The frequency response function reveals how partially saturated sediment minimizes the influence of the geometry of the upstream reservoir, far from the dam, in the seismic response of the structure. In this case it only seems necessary to model in detail the characteristics of the reservoir in the regions close to the dam. As previously seen and confirmed in earlier works, the frequency response of the structure decreases when there are sediments, especially for incident $\mathrm{P}$-waves and according to the increase in the water height of the reservoir.

The acceleration response spectra is dominated

2.- The acceleration response spectrum along the canyon axis in the dam abutment for $\mathrm{S}$ waves in the same direction is dominated by the local effect associated with the scattering caused by the canyon. After studying all of the combinations for reservoir conditions and all the different points, no significant differences are observed with respect to the results obtained from the problem of free field with the effect caused by the canyon. However the behavior of this variable is different for the excitation given by a P-wave. In this case, the reservoir condition affects the response to a greater extent and is more pronounced for points closer to the bottom of the reservoir.

3.- Versus the analysis of frequency response functions of the points along the dam crest, the present study clearly reveals that, when the response is measured in terms of the integral of squared velocity, important differences can be observed according to the upstream reservoir geometry. That is, the obtained values of this variable are notably different depending on the distant upstream geometry, especially if sediments are included in the model, or the geometry of the reservoir changes for intermediate water levels, even without sediments. These differences are shown in the two cases of excitations, although they are more apparent in the P-wave excitation case.

Also, as seen with others response quantities used, smaller reservoir levels reduce the dam response in a more obvious way when there are bottom sediments. Nevertheless, a clear relationship between the degree of saturation, the upstream reservoir geometry and the response of the structure in terms of this variable cannot be established for the water heights studied. It can only be concluded that, in relation to the reservoir geometry and conditions, modeling must be carried out with the utmost care for the entire area, not only in the areas close to the dam, as confirmed by the presented results. 


\section{Acknowledgements}

This work was supported by the Subdirección General de Proyectos de Investigación of the Ministerio de Economía y Competitividad (MINECO) of Spain and FEDER through research projects BIA2010-21399-C02-01/02 and also by the Agencia Canaria de Investigación, Innovación y Sociedad de la Información (ACIISI) of the Government of the Canary Islands and FEDER through research project ProID20100224. The authors are grateful for this support.

\section{References}

[1] Hall, J., \& Chopra, A.K. (1982). Hydrodynamic Effects in the Response of Concrete Gravity Dams. Earthquake Engineering and Structural Dynamics, 10(2), 333-345.

[2] Hall, J., \& Chopra, A.K. (1983). Dynamic Analysis of Arch Dams Including Hydrodynamic Effects. Journal of Engineering Mechanics. ASCE, 19(3), 496-512.

[3] Fenves, G., \& Chopra, A.K. (1985). Effects of Reservoir Bottom Absorption and DamWater-Foundation Rock Interaction on Frequency Response Functions for Concrete Gravity Dams. Earthquake Engineering and Structural Dynamics, 13(1), 13.31.

[4] Cheng, A. H. D. (1986). Effect of Sediment on Earthquake-Induced Reservoir Hydrodynamic Response. Journal of Engineering Mechanics, 112(7), 654-665.

[5] Fok, K., \& Chopra, A.K. (1987). Water Compressibility in Earthquake Response of Arch Dams. Journal of Structural Engineering. ASCE, 113(5), 958-975.

[6] Bougacha, S., \& Tassoulas, J. L. (1991). Seismic Response of Gravity Dams II: Effects of Sediments. J. Eng. Mech., 117(8), 1839-1850.

[7] Chen, B., \& Hung, T. (1993). Dynamic Pressure of Water and Sediment on Rigid Dam. Journal of Engineering Mechanics, 119(7), 1411-1433.

[8] Tan, H., \& Chopra, A.K. (1995). Earthquake Analysis of Arch Dam Including DamWater-Foundation Rock Interaction. Earthquake Engineering and Structural Dynamics, $24,1453-1474$.

[9] Domínguez, J., \& Maeso, O. (1993). Effects of the Space Distribution of the Excitation on the Seismic Response of Arch Dams. Journal of Engineering Mechanics. ASCE, 119(3), 513-530.

[10] Maeso, O., Aznárez, J.J., \& Domínguez, J. (2002b). Numerical Model for Dynamic 
Behavior of Reservoir Botton Sediments. En A. e. al. (Ed.), Proc. 2nd Biot Conf. on Poromechanics, (págs. 709-714). Balkema, Rotterdam.

[11] Aznárez, J.J., Maeso, O., \& Domínguez, J. (2006). B.E. Analysis of Bottom Sediments in Dynamic Fluid-Structure Interaction Problems. Engineering Analysis With Boundary Elements, 30, 124-136.

[12] Bougacha, S., \& Tassoulas, J. (2006). Dam-Water-Sediment-Rock Systems: Seismic Analysis. Soil Dynamics and Earthquake Engineering, 26, 680-693.

[13] Gogoi, I., \& Maity, D. (2007). Influence of Sediment Layers on Dynamic Behavior of Aged Concrete Dams. Journal of Engineering Mechanics. ASCE, 133(4), 400-413.

[14] Bouaanani, N., \& Lu, F. (2009). Assessment of Potential-Based Fluid Finite Elements for Seismic Analysis of Dam-Reservoir Systems. Computers and Structures, 87(3-4), 206224.

[15] Sani, A., \& Lotfi, V. (2011). An Effective Procedure for Seismic Analysis of Arch Dams Including Dam-Reservoir-Foundation Interaction Effects. Journal of Earthquake Engineering, 15(7), 971-988.

[16] Dabre, G., de Smet, C., \& Fraemer, C. (2000). Natural Frequencies Measured from Vibration Response of the Arch dam of Mauvoisin. Earthquake Engineering and Structural Dynamics, 29, 577-586.

[17] Proulx, J., Paultre, P., Rheault, J., \& Robert, Y. (2001). An Experimental Investigation of Water Level Effects on the Dynamic Behaviour of a Large Arch Dam. Earthquake Engineering and Structural Dynamics, 30, 1147-1166.

[18] Domínguez, J., Gallego, R., \& Japón, B. R. (1997). Effects of Porous Sediments on Seismic Response of Concrete Gravity Dams. Journal of Engineering Mechanics. ASCE, 123(4), 302-311.

[19] Aznárez, J.J. (2002). Efectos de los Fenómenos de Interacción Incluyendo Factores Espaciales y Sedimentos de Fondo en la Respuesta Sísmica de Presas Bóveda. (http://bibmdc.ulpgc.es/cdm/ref/collection/POSTULPGC/id/1211). Universidad de Las Palmas de Gran Canaria.

[20] Maeso, O., Aznárez, J.J., \& Domínguez, J. (2004). Three-Dimensional Models of Reservoir Sediment and Effects on Seismic Response of Arch Dams. Earthquake Engineering and Structural Dynamics, 33, 1103-123. 
[21] Biot, M. A. (1956b). Theory of Propagation of Elastic Waves in a Fluid-Saturated Porous Solid. I: Low Frequency Range. Journal of the Acoustical Society of America, 28(2), 168-178.

[22] Verruijt, A. (1969). Elastic Storage of Aquifers. En R. J. Weist (Ed.), Flow through porous media (págs. 331-376). Academic Press New York.

[23] Maeso, O., Aznárez, J. J., \& Domínguez, J. (2002). Effects of the Space Distribution of the Excitation on the Seismic Response of Arch Dams. Journal of Engineering Mechanics. ASCE, 128 (7), 759-768.

[24] Medina, F., \& Domínguez, J. (1989). Boundary Elements for the Analysis od Dams Including Dam-Water-Foundation Interaction Effects I. Engineering Analysis with Boundary Elements, 6, 151-157.

[25] CEN. European Committee for Standardization. (2004). EN 1998-1:2004:E. Design of structures for Earthquake Resistence (Vols. Part 1: General Rules, Seismic Actions and Rules for Buildings).

[26] Vanmarcke, E. H., Corneli, C. A., Gasparini, D. A., \& Hou, S. N. (1976). SIMQKE. Simulation of Earthquake Ground Motions. Massachusetts Institute of Technology, Cambridge, Massachusetts, USA.

[27] Kausel, E., \& Ushijima, R. (1979). Baseline Correction of Earthquake Records in the Frequency Domain. Research Report R79-34, Massachusetts Institute of Technology, Cambridge, USA.

[28] García, F. (2012). Comportamiento Dinámico de Medios Poroelásticos en Relación con Problemas de Interacción Suelo-Estructura y Suelo-Agua-Estructura. (http://acceda.ulpgc.es/handle/10553/9816). PhD Thesis Universidad de Las Palmas de Gran Canaria (in Spanish). 